\section{Ethics, prevention and public health}

Editors: Angus Dawson \& Marcel Verweij Publisher: Clarendon Press, Oxford, 2007 ISBN-13: 978-0-19-929069-7; hardcover; 256 pages; price £35

Public health ethics has been receiving increased attention in recent years. Often, public health practitioners have to confront complex decisions, with numerous and often conflicting ethical implications. What to do: ask colleagues? try a literature review? consult a specialist in bioethics? The title of this book raises expectations of a treatise on the subject - a refuge for the public health practitioner with disconcerting questions.

As stated in its preface, the book has come about as a result of encounters and discussions at meetings of the International Association of Bioethics held over several years. Some of the chapters result from a research seminar held in the Netherlands in 2002, while others have been written subsequently. The sixteen authors of the twelve chapters, all of which are original, come from Europe and North America, and range from a PhD student to luminaries in this field, such as Lawrence $\mathrm{O}$ Gostin.

The book is very well structured, starting with an introductory chapter by the editors, Angus Dawson and Marcel Verweij, that provides an overview of what follows and discusses three general features of public health interventions. First, the initiative for public health interventions usually comes from a public health professional and not a patient who is seeking care; second, public health interventions may not be beneficial for each individual, but aim to protect and promote health at the group or population level; and third, public health activities are potentially pervasive and can interfere with all aspects of life and of society.
The topics covered range from vaccination and herd protection as a public good, a non-paternalistic argument for tobacco discouragement, to the use of cost-effectiveness analysis for priority-setting. Most readers will restrict themselves to one or two chapters, with probably only a very few reading it from cover to cover.

Personally, the book has enabled me to get a better grip on an issue that I have had in the back of my mind for some years. While informed consent is the hallmark of bioethics in health services, the complexity of interventions at the group and population levels makes it difficult to use the same standard for public health activities. For example, the increased use of combined vaccines in universal vaccination programmes (such as adding also a vaccine against chickenpox to measles, mumps and rubella vaccine) makes it impossible for parents to provide informed consent to each of the component vaccines involved. Although the individual and collective benefit and risk levels are different for each individual vaccine, a parent can at best only provide consent to a combined vaccine programme.

In the final chapter of the book, Niels Nijsingh argues compellingly that requiring informed consent for a dramatically expanded newborn screening programme places too severe a burden on both parents and society in general, and that we need to find other means for protecting the individuals participating in public health programmes. Such an argument may be shocking to some, but it shows that this book does not provide ready-made answers for public health practitioners stumbling over ethical issues. Rather, it forces readers to reflect on these issues, deepen their understanding and arrive at conclusions that should be discussed with others.

\section{Reiner Banken}

\section{Traditional, complementary and alternative medicine: policy and public health perspectives}

Editors: Gerard Bodeker and Gemma Burford, Publisher: Imperial College Press, London, 2007

ISBN: 978-1-86094-616-5; hardcover; 472 pages; price £47

The seventeen chapters of this book deal with a wide range of issues on traditional medicine: policy (10 chapters), public health issues ( 5 chapters) and research ( 4 chapters). Each chapter has been authored by one or more international experts. In their introduction, the editors, Bodeker and Burford indicate that the book represents " $\mathrm{a}$ first attempt at generating a systematic global overview" of traditional medicine in the context of its increasing globalization.

Traditional medicine is an amorphous concept that comprises a range of long-standing and still evolving practices based on diverse beliefs and theories. Bodeker and Burford point out the dichotomous situation of particular forms of traditional medicine being practised in their countries of origin and also in countries to which they have been "imported". They suggest that the term "traditional, complementary and alternative medicine" (TCAM) is a more appropriate term to describe such traditional therapies globally.

Health care can broadly be divided into modern (conventional, orthodox, Western or allopathic) and traditional (indigenous, complementary, alternative or integrative). The former is clearly defined, with minor regional variations in its underlying philosophy and clinical methods. In modern medicine, knowledge expansion is achieved through scientific research, which can involve global collaboration and commitment. Such research is well

\footnotetext{
a Agence d'évaluation des technologies et des modes d'intervention en santé, 2021 avenue Union, bureau 10.083, Montreal H3A 2S9, Canada. Correspondence to Reiner Banken (e-mail: reiner.banken@aetmis.gouv.qc.ca).
} 
supported financially by industry, governments and philanthropic organizations. This is in sharp contrast to the situation with TCAM.

The book argues that education is a critical means of ensuring safe and effective practice of TCAM. However, levels of education vary substantially from country to country, and in many countries, the current curricula may not be adequate enough to ensure that the potential benefits of various forms of TCAM therapies are fully realized. Different education needs should be met, such as specific public health education for HIV/AIDS. The gap in education provision is also attributed to "a lack of funding and/or political will”.

The health benefits of TCAM have not so far been fully assessed in ways that can be universally accepted as being evidence based. This is partly due to the philosophical differences and cultural barriers between the countries where such therapies originated and the Western countries where they are now also being practised. Much of the research on TCAM is of questionable quality and often it does not use modern scientific techniques. The book proposes that a combined political and scientific approach will be necessary to provide for a comprehensive research agenda targeted at establishing the potential risks and benefits of TCAM. Only then will health-care professionals be in a position to make informed decisions about the use of TCAM therapies alongside those of conventional Western therapies.
With the effective leadership of WHO, a number of countries have developed traditional medicine policies; however, appropriate funding for traditional medicine research has generally not been forthcoming. It is argued in the book that the extent to which individual countries, particularly Western countries, have actually committed to supporting TCAM can be measured in terms of the funding that has been allocated to research and practice. Research efforts in Western countries have been largely concerned with the quality, safety and efficacy of only certain forms of TCAM, such as herbal medicine and acupuncture. Such a focus on herbal medicine may be due to the perceived higher level of risk associated with its practice and also because of its potential for exploitation in drug discovery. For some modalities of TCAM, there has been significant progress towards the development of an underpinning evidence base, for example, the research on Artemisia spp. for treatment of malaria.

Several of the contributors to the book maintain that there needs to be a better understanding of the reasons for the sudden rise in the popularity of TCAM in the developed world. They argue that in the growing use of "imported" traditional therapies, there has been a failure to properly acknowledge the traditions and practices of the communities where they originated. The intellectual property rights associated with the knowledge embodied in the TCAM therapies is another important issue that is discussed in some detail in the book. Moreover, practitioners, researchers and consumers in developed countries do not seem to appreciate the efforts and significant resources that are now being made available to "modernize" TCAM.

The impressive team of contributors to this book foreshadows its likely impact on the ongoing integration of the main forms of TCAM and modern medicine. The book provides an overview of the many and complex issues surrounding the expanding use of TCAM. It will be of value to government policymakers, regulators, researchers and health-care practitioners.

\section{Charlie Changli Xue}

\footnotetext{
a World Health Organization Collaborating Centre for Traditional Medicine; and Division of Chinese Medicine, School of Health Sciences, RMIT University, Melbourne, Australia.

Correspondence to Charlie Changli Xue (e-mail: Charlie.xue@rmit.edu.au).
} 